\title{
Effect of the Melatonin on Morning Blood Pressure Surge and Norepinephrine Endovenous Infusion in Healthy Volunteers
}

\author{
Jaime Carranza-Madrigal1 ${ }^{*}$, José Miguel Cervantes-Alfaro ${ }^{2}$, Sonia María López-Correa1 \\ ${ }^{1}$ Escuela de Enfermería y Salud Pública, Universidad Michoacana de San Nicolás de Hidalgo, Morelia, México \\ 2División de Estudios de Postgrado, Facultad de Ciencias Médicas y Biológicas “Dr. Ignacio Chávez”, Universidad \\ Michoacana de San Nicolás de Hidalgo, Morelia, México \\ Email: ${ }^{*}$ jcmavocat@yahoo.com.mx
}

Received 4 June 2015; accepted 30 June 2015; published 3 July 2015

Copyright @ 2015 by authors and Scientific Research Publishing Inc.

This work is licensed under the Creative Commons Attribution International License (CC BY).

http://creativecommons.org/licenses/by/4.0/

(c) (i) Open Access

\begin{abstract}
Melatonin, the pineal gland hormone, has been considered as a central hypotension factor. However their roles in the regulation of the human blood pressure and its possible use as antihypertensive drug have not been fully determined. The objective of this trial was to determine the effect of melatonin on blood pressure morning increase and a peripheral vasoconstriction challenge in healthy volunteers. Twelve healthy male volunteers were included in a prospective, comparative, randomized, crossover trial in which changes on blood pressure (BP) and heart rate (HR) after the first morning orthostatism and endovenous norepinephrine (NE) infusion were measured one hour after the administration of placebo (PL) or $10 \mathrm{mg}$ of melatonin in double blind conditions. Melatonin blunted the effects of the first orthostatism on BP and HR. Melatonin also reduces the pressor effect of NA. One concludes that melatonin has central and peripheral hypotensive effects that support a potential role of this hormone in cardiovascular therapeutics.
\end{abstract}

\section{Keywords}

Blood Pressure, Hypertension, Melatonin, Norepinephrine, Orthostatism

\section{Introduction}

Melatonin is the major pineal secretion; it has been related to blood pressure control and in several experimental [1] [2] and clinical trials it has demonstrated antihypertensive effects [3] [4]. Their hypotensive effects may be

\footnotetext{
"Corresponding author.
} 
central [5] and peripheral [6] which have been proved in several experimental trials. However their effects on central physiological activation of adrenergic system after first morning orthostatism and its effects on peripheral responses to adrenergic influence have not been evaluated in humans. Because it is necessary to evaluate the effect of the hormone on the blood pressure morning surge and on the norepinephrine pressor effect in order to determine the level of the antihypertensive actions of melatonin in humans.

\section{Methods}

Twelve healthy volunteer men were included in a prospective, randomized, comparative, crossover, placebo controlled, double blind trial in which each subject served as both an experimental subject and control. Their characteristics are shown in Table 1. All the subjects had normal laboratory (haematological citometry; serum glucose, creatinine, urea and uric acid; urinalysis) and EKG values. None of the volunteers had parental history of hypertension and they were selected from 29 subjects aged 18 to 35 years after three stressor stimuli: orthostatism, cold water vasopressor stimulus and mathematical stress. The volunteers with diastolic blood pressure elevations $\geq 90 \mathrm{~mm} \mathrm{Hg}$ in response to stress were discharged from the study.

\subsection{First Morning Standing Effects}

Volunteers were interned in a clinical research unit on day -1 at 18:00 h, they were asked for medical history and they were subjected to physical examination, a standardized meal was administered at 20:00 $\mathrm{h}$ followed by a sleep period from the 23:00 to 07:00 $\mathrm{h}$ of day 1 . At this time volunteers were waked up to receive $10 \mathrm{mg}$ of melatonin o placebo, but they stayed in supine position. At 8:00 three supine blood pressure measurements were carried out and immediately they assumed the standing position and blood pressure was measured each 30 seconds during ten minutes. Treatments were crossed in double blind conditions one week after.

\subsection{Norepinephrine Infusion Effects}

In other two experimental sessions procedures were repeated but volunteers stayed in supine position to receive an endovenous infusion of norepinephrine at three progressive doses: 6.6, 8 and $9.3 \mathrm{mcg} / \mathrm{min}$ lasting three minutes each. Infusion was stopped at 9 minutes or when a $30 \mathrm{~mm} \mathrm{Hg}$ systolic blood pressure increase (SBP) was reached. Blood pressure measurements were made with a validated Omrom HEM-601 wrist electronic device [7].

\subsection{Statistical Analysis}

Descriptive statistics with mean and standard deviation were carried out. To compare means of continuous variables paired student " $t$ " test was made. To analyze differences in categorical variables chi square test was calculated. To compare temporary changes on blood pressure respect to control values variance analysis with Dunnet "t" test were carried out. P values $<0.05$ were considered statistically significant.

\subsection{Ethical Considerations}

The study was approved by our Internal Ethics Committee and it was conducted in agreement with the last revision of Helsinki's Declaration, the Good Clinical Practices and the International Conference of Harmonization.

Table 1. Characteristics of studied population.

\begin{tabular}{ccc}
\hline Feature & Mean & Standard Deviation \\
\hline Age (years) & 21.3 & 2.6 \\
Weight (kg) & 66.02 & 7.1 \\
Height (m) & 1.7 & 0.07 \\
Body Mass Index & 22.5 & 2.01 \\
\hline
\end{tabular}




\section{Results}

Table 2 and Figures 1-3 show the blood pressure (BP) and heart rate (HR) values during the first morning orthostatism stimulus. The change of position induced an increase in SBP and DBP that reaches its maximum in the first measurement after standing; it was made between 30 and 45 seconds after orthostatism. There is a progressive decrement en BP until five minutes when it tends to stabilize but remains $10 \mathrm{~mm} \mathrm{Hg}$ for SBP and $5 \mathrm{~mm}$ Hg for DBP above supine values. HR had a maximum increment during first seconds after standing with a fast lowering and stabilization approximately 20 beats above the supine value. Melatonin blunted the initial SBP, DBP and HR increments and maintained BP below placebo values during ten-minute orthostatism. Figure 4 illustrates the area under the curve (AUC) of BP and HR response to first morning orthostatism under melatonin and placebo influences. It shows that melatonin administered one hour before standing blunted the SBP and DBP responses without any changes on HR orthostatic increment.

During norepinephrine (NE) with placebo all subjects but one reached the security delta of $30 \mathrm{~mm} \mathrm{Hg}$ increase in SBP. Two volunteers required less NE dose to reach the SBP delta with placebo and seven did it with melatonin; two of them did not reach the $30 \mathrm{~mm} \mathrm{Hg}$ increase during whole infusion. The only one subject that

Table 2. BP and HR values in supine position and after first morning orthostatism. $\mathrm{S}=$ supine, 1 to $21=$ standing measurements.

\begin{tabular}{|c|c|c|c|c|c|c|}
\hline \multirow[b]{2}{*}{ Measurement } & \multicolumn{3}{|c|}{ Placebo } & \multicolumn{3}{|c|}{ Melatonin } \\
\hline & SBP & DBP & HR & SBP & DBP & HR \\
\hline S & $107.6 \pm 1.4$ & $62.1 \pm 1.2$ & $58.4 \pm 1.4$ & $109.6 \pm 1.5$ & $61.8 \pm 1.1$ & $60.6 \pm 1.3$ \\
\hline 1 & $132.2 \pm 5.7^{*}$ & $78.7 \pm 2.8^{*}$ & $96.1 \pm 4.5^{*}$ & $118.8 \pm 3.1^{*}$ & $66.8 \pm 3.1^{*}$ & $82 \pm 6.6$ \\
\hline 2 & $126.9 \pm 3.6^{*}$ & $79.5 \pm 2.7^{*}$ & $83.2 \pm 5.6^{*}$ & $124.4 \pm 4.7^{*}$ & $76 \pm 3.4^{*}$ & $84.3 \pm 5.2^{*}$ \\
\hline 3 & $122.6 \pm 3.6^{*}$ & $77.4 \pm 2.3^{*}$ & $83.7 \pm 5.4^{*}$ & $120.5 \pm 3.4^{*}$ & $71.8 \pm 3.2^{*}$ & $81.4 \pm 3.6^{*}$ \\
\hline 4 & $120.5 \pm 3.5^{*}$ & $75.2 \pm 2.6^{*}$ & $81.8 \pm 5.4^{*}$ & $119.4 \pm 5^{*}$ & $72.8 \pm 2.8^{*}$ & $83.1 \pm 4.4^{*}$ \\
\hline 5 & $121.5 \pm 4^{*}$ & $72.7 \pm 2.7^{*}$ & $83.5 \pm 4.9^{*}$ & $116.4 \pm 3.1^{*}$ & $70.9 \pm 3.7^{*}$ & $84.5 \pm 5.5^{*}$ \\
\hline 6 & $122.9 \pm 3.8^{*}$ & $72.6 \pm 2.9^{*}$ & $81.8 \pm 4.4^{*}$ & $114.6 \pm 3.5^{*}$ & $70.1 \pm 3.5^{*}$ & $86.5 \pm 4.6^{*}$ \\
\hline 7 & $121.4 \pm 3.2^{*}$ & $70.4 \pm 2.8^{*}$ & $82.6 \pm 4.7^{*}$ & $113.3 \pm 3.8$ & $69.6 \pm 3.5^{*}$ & $86.7 \pm 4.8^{*}$ \\
\hline 8 & $118.7 \pm 3.7^{*}$ & $70.9 \pm 2.7^{*}$ & $81.8 \pm 4.6^{*}$ & $115.3 \pm 4.2^{*}$ & $69.3 \pm 3.4^{*}$ & $83.3 \pm 4.4^{*}$ \\
\hline 9 & $117.9 \pm 3.1^{*}$ & $69.3 \pm 2.9^{*}$ & $83.2 \pm 4.6^{*}$ & $115.7 \pm 3.8^{*}$ & $66.5 \pm 3.2$ & $85.3 \pm 4.1^{*}$ \\
\hline 10 & $115.5 \pm 3.1^{*}$ & $67.4 \pm 3^{*}$ & $83.8 \pm 4.6^{*}$ & $114.8 \pm 4.2^{*}$ & $64.4 \pm 3.2$ & $85.5 \pm 3.1^{*}$ \\
\hline 11 & $118.8 \pm 3.3^{*}$ & $66.3 \pm 3.1$ & $84 \pm 5.1^{*}$ & $114.6 \pm 4.9^{*}$ & $65.3 \pm 3.4$ & $83.1 \pm 3^{*}$ \\
\hline 12 & $116.6 \pm 3.5^{*}$ & $68.6 \pm 2.9^{*}$ & $82.9 \pm 4.4^{*}$ & $118.4 \pm 4.8^{*}$ & $64.3 \pm 2.8$ & $80.3 \pm 5.1^{*}$ \\
\hline 13 & $114.9 \pm 2.7^{*}$ & $67.8 \pm 2.8^{*}$ & $83.3 \pm 4.3^{*}$ & $116.1 \pm 4.3^{*}$ & $66.5 \pm 3.5$ & $84.5 \pm 4.8^{*}$ \\
\hline 14 & $116.3 \pm 3.5^{*}$ & $64.4 \pm 3.9$ & $83.8 \pm 4.9^{*}$ & $112.5 \pm 4.4$ & $66 \pm 3.6$ & $83.4 \pm 4.4^{*}$ \\
\hline 15 & $115.1 \pm 4.1^{*}$ & $63.8 \pm 4.1$ & $81 \pm 5.1^{*}$ & $111.1 \pm 4.4$ & $63.5 \pm 4$ & $83.6 \pm 5.6^{*}$ \\
\hline 16 & $119.3 \pm 3.8^{*}$ & $68.3 \pm 3.6^{*}$ & $81.3 \pm 4.4^{*}$ & $111 \pm 4.2$ & $64 \pm 3$ & $83.9 \pm 3.7^{*}$ \\
\hline 17 & $117.2 \pm 4.2^{*}$ & $67.8 \pm 4.1$ & $80.2 \pm 4.4^{*}$ & $114.1 \pm 3.7$ & $66.1 \pm 2.9$ & $83.4 \pm 3.8^{*}$ \\
\hline 18 & $115.9 \pm 4^{*}$ & $67.8 \pm 4.8$ & $81.4 \pm 4.8^{*}$ & $114.9 \pm 3.9$ & $65.3 \pm 3.1$ & $83.3 \pm 4.1^{*}$ \\
\hline 19 & $116.6 \pm 4^{*}$ & $69.6 \pm 2.9^{*}$ & $82.3 \pm 6^{*}$ & $116 \pm 4.5^{*}$ & $66.6 \pm 3$ & $84.8 \pm 4.1^{*}$ \\
\hline 20 & $118.9 \pm 3.2^{*}$ & $69 \pm 3^{*}$ & $80.8 \pm 4.6^{*}$ & $115.5 \pm 4.1^{*}$ & $67.7 \pm 3.1^{*}$ & $86 \pm 2.9^{*}$ \\
\hline 21 & $121 \pm 5.6^{*}$ & $69.2 \pm 2.7^{*}$ & $84.6 \pm 4.6^{*}$ & $111.9 \pm 3.8$ & $64.2 \pm 2.5$ & $81.5 \pm 3.4^{*}$ \\
\hline
\end{tabular}

\footnotetext{
${ }^{*}=\mathrm{p}<0.05$ vs C.
} 


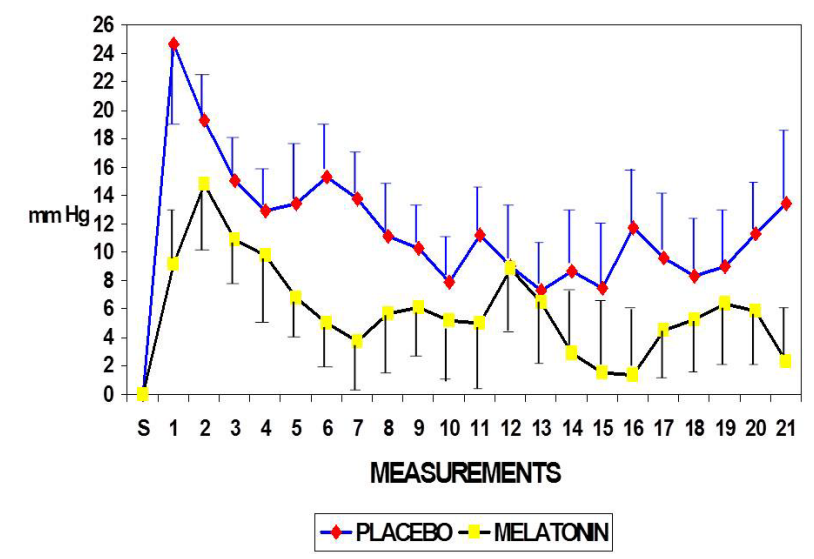

Figure 1. Differences in SBP orthostatic response respect to supine values (mean and $\mathrm{SD}$ ) $\mathrm{S}=$ supine, 1 to $2=$ standing measurements.

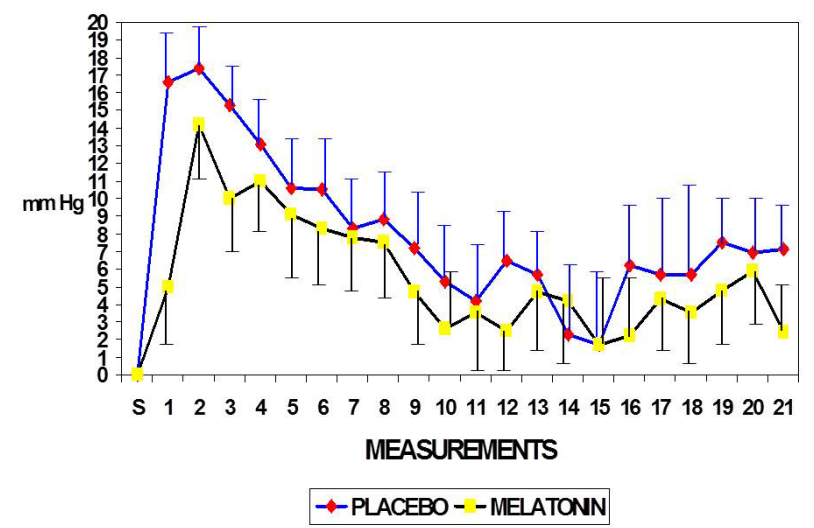

Figure 2. Differences in DBP orthostatic response respect to supine values (mean and SD) $\mathrm{S}=$ supine, 1 to 21 = standing measurements.

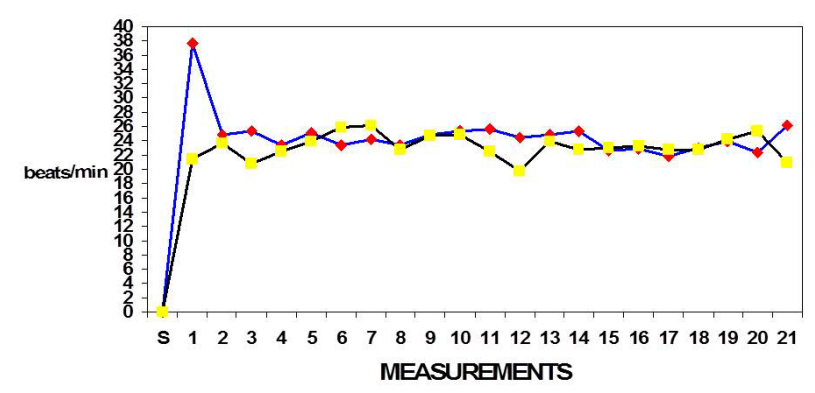

$\rightarrow-$ PLACEBO - - MELATONIN

Figure 3. Differences in HR orthostatic response respect to supine values (mean and SD) $\mathrm{S}=$ supine, 1 to 21 = standing measurements.

did not reach the SBP delta with placebo neither did it with melatonin. Blood pressure values obtained during $\mathrm{NE}$ infusion were lower with melatonin respect to placebo and there were two volunteers with decreasing SBP values respect to control. Table 3 illustrates NE dose, total volume infused and lasting time of infusion for each volunteer under both placebo and melatonin. It shows that melatonin induced an increment in NE dose, volume and time of infusion to reach the SBP goal. In Figure 5 one observes the AUC of the NE dose needed to reach 
Table 3. NE requirements to reach the $30 \mathrm{~mm} \mathrm{Hg}$ difference in SBP.

\begin{tabular}{|c|c|c|c|c|c|c|}
\hline \multirow[b]{2}{*}{ Subject } & \multicolumn{3}{|c|}{ PLACEBO } & \multicolumn{3}{|c|}{ MELATONIN } \\
\hline & Dose (mcg) & Volume (ml) & Time (min) & Dose (mcg) & Volume (ml) & Time (min) \\
\hline 1 & 105.6 & 4.9 & 14.5 & 165.6 & 7.2 & 21.7 \\
\hline 2 & 188 & 8 & 25.8 & 216 & 9 & $27^{*}$ \\
\hline 3 & 216 & 9 & $27^{*}$ & 216 & 9 & $27^{*}$ \\
\hline 4 & 40 & 2 & 6 & 216 & 9 & $27^{*}$ \\
\hline 5 & 26 & 1.3 & 4.5 & 84 & 4 & 13.8 \\
\hline 6 & 24 & 1.2 & 3.75 & 16 & 0.8 & 2.25 \\
\hline 7 & 30 & 1.5 & 5.25 & 48 & 2.4 & 7.5 \\
\hline 8 & 60 & 3 & 7.8 & 74.4 & 3.6 & 11.4 \\
\hline 9 & 137.6 & 6.2 & 18.5 & 88.8 & 4.2 & 14.25 \\
\hline 10 & 171.2 & 7.4 & 22.5 & 216 & 9 & $27^{*}$ \\
\hline 11 & 20 & 1 & 3.75 & 40 & 2 & 6 \\
\hline 12 & 84 & 4 & 11.5 & 96 & 4.5 & 13.1 \\
\hline Mean \pm SD & $91.8 \pm 70.6^{* *}$ & $4.1 \pm 2.9^{* *}$ & $12.5 \pm 8.8$ & $123.06 \pm 77.5$ & $5.3 \pm 3.07$ & $16.5 \pm 9.1$ \\
\hline
\end{tabular}

*30 mm Hg delta was not reached; ${ }^{* *} \mathrm{p}<0.05$ vs melatonin.

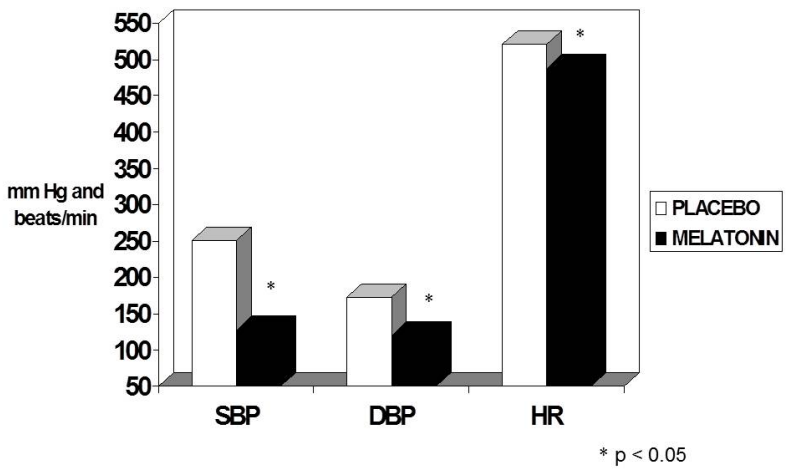

Figure 4. Area under the curve of the BP and HR response to orthostatism.

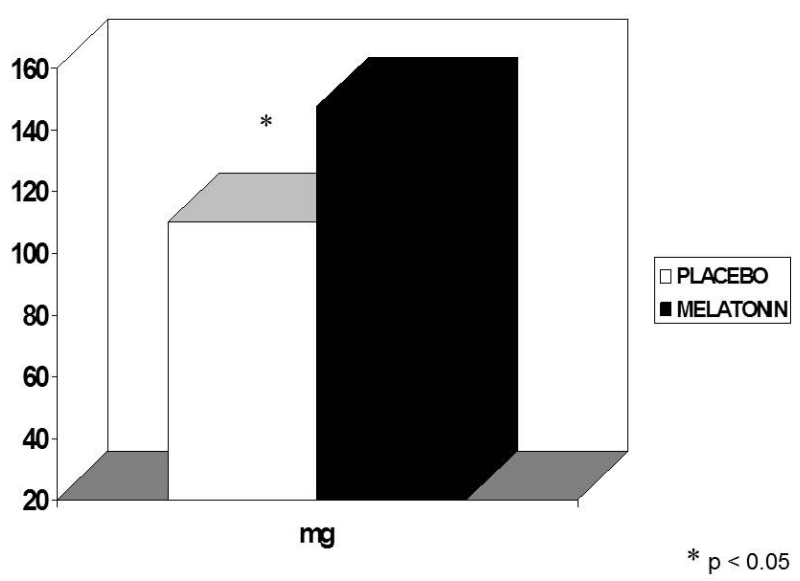

Figure 5. Total NE dose required to reach a SBP $30 \mathrm{~mm} \mathrm{Hg}$ increase. 
the SBP $30 \mathrm{~mm}$ Hg delta; it shows that melatonin induced a significant increase in NE requirement to achieve the BP goal.

\section{Discussion}

Although several mechanisms have been postulated to explain the descent of the BP caused by melatonin [8], it has not been explored sufficiently the level of their antihypertensive effect in humans. Our data show that melatonin blocks the elevation of the BP and the HR in response to the first morning orthostatism. It is well known that patients who experience surges of blood pressure after arising are at risk for stroke and likely other cardiovascular events [9]. Sudden activation of the sympathetic nervous system is the primary mediator of the morning surge. Increased-mediated sympathetic vasoconstriction has been found in normal subjects [10]. Whereas arousal from sleep is associated with a slight rise in plasma epinephrine, arising induces a significant rise both in epinephrine and norepinephrine [11]. The circulatory adaptation to the orthostatism is a sympathetic reflex integrated at central level in the nuclei of the pressor rostral ventrolateral area of the oblongate medulla, which when liberated of the inhibition exercised by the baroreceptors increases the noradrenergic outflow leading to: increase of the heart frequency, liberation of catecholamines from the adrenal medulla, descent in the venous compliance and increase of the peripheral vascular resistances; all this leads to elevation of the BP dedicated to maintaining an appropriate cerebral blood flow. The fact that melatonin reduces as much the BP as the HR after the first morning orthostatism suggests a central antihypertensive action by inhibition of the sympathetic tone of the medullar vasopressor centers.

The endovenous infusion of low dose of norepinephrine causes stimulation predominantly of type $\alpha$-adrenergic, which produces an increment of the peripheral resistances and an increase of the blood pressure. Melatonin administered one hour before beginning the infusion of NE reduces the pressor effect of this amine; this suggests an action at peripheral level; this vasodilating action has been previously described especially in diverse experimental models in those that have been demonstrated that melatonin reduces the vasoconstriction induced by pressor agents, specially of those whose effect depends on increasing the citosolic $\mathrm{Ca}$ in the vascular smooth muscle [12]. Melatonin has not been demonstrated effects through adrenergic receptors, and rather the experimental evidence suggests a basal sympathetic inhibition and intracellular effects of the hormone [13]; one of them is the antagonism that the melatonin exercises on the calmoduline, enzyme that regulates varies of the intracellular actions of the calcium and that in the vascular smooth muscle it is essential for the activation of the myosin light chain kinase, which is a necessary requirement for the interaction of this contractile protein with actine; this myosin light chain kinase may be activated by oxidized low-density lipoprotein (LDL) and melatonin has demonstrated in human vascular endothelium cells cultures that it can prevent this activation [14]. Another possible mechanism is the anti-oxidant effect of melatonin, demonstrated in models of damage to the DNA for oxygen free radicals [15] and also in models of endothelium dysfunction and LDL oxidation where it is recognized with more force the importance that oxygen and nitrogen reactive species have on the vasodilating function of the vascular endothelium [16]. Another possibility is the indirect inhibition that melatonin has on phosphodiesterase [17] what would increase the levels of GMPc in the vascular smooth cells causing peripheral vasodilatación. Melatonin has proven antioxidant effects on NE induced lipid peroxidation along with an elevation of NO and cyclic GMP levels in endothelial cells [18].

They lack several aspects to study before establishing the utility of the melatonin as antihypertensive therapy. The first one is to know if the results reported in this study are reproducible in "hyper-reactive" or "prehypertensive" subjects. The second is to know if the hypertensive patients have a pattern of similar response to melatonin. And the last is to elucidate the best dose and the appropriate time of melatonin administration, as well as to settle down if the hormone can be used as monotherapy or in combination with other antihypertensive drugs. However our trial shows that melatonin is able to blunt the natural sympathetic arising of the first morning orthostatism and to reduce the pressor effects of NE in pharmacological conditions. This confers to the hormone's potential use as a treatment for cardiovascular pathologies.

\section{References}

[1] Zanoboni, A., Forni, A., Zanoboni-Muciaccia, W., et al. (1978) Effect of Pinealectomy on Arterial Blood Pressure and Food and Water Intake in the Rat. Journal of Endocrinological Investigation, 1, 125-130. http://dx.doi.org/10.1007/BF03350359 
[2] Holmes, S.W. and Sugden, D. (1976) The Effect of Melatonin on Pinealectomy-Induced Hypertension in the Rat. British Journal of Pharmacology, 56, 360-361.

[3] Cagnacci, A., Arangino, S., Angiolucci, M., et al. (1998) Influences of Melatonin Administration on the Circulation of Women. American Journal of Physiology, 274, R335-R338.

[4] Arangino, S., Cagnacci, A., Angiolucci, M., et al. (1999) Effects of Melatonin on Vascular Reactivity, Catecholamine Levels, and Blood Pressure in Healthy Men. American Journal of Cardiology, 83, 1417-1419. http://dx.doi.org/10.1016/S0002-9149(99)00112-5

[5] Girouard, H., Denault, C., Chulak, C.H., et al. (2004) Treatment by N-Acetylcysteine and Melatonin Increase Cardiac Baroreflex and Improves Antioxidant Reserve. American Journal of Hypertension, 17, 947-954. http://dx.doi.org/10.1016/j.amjhyper.2004.06.009

[6] Anwar, M.M., Meki, A.R. and Abu Rahma, H.H. (2001) Inhibitory Effects of Melatonin on Vascular Reactivity: Possible Role of Vasoactive Mediators. Comparative Biochemistry and Physiology Part C, 130, 357-367. http://dx.doi.org/10.1016/s1532-0456(01)00261-7

[7] Kikuya, M., Chonan, K., Imai, Y., Goto, E. and Masao, I. (2002) On Behalf of the Research Group. Accuracy and Reliability of Wrist-Cuff Devices for Self-Measurement of Blood Pressure. Journal of Hypertension, 20, 629-638. http://dx.doi.org/10.1097/00004872-200204000-00019

[8] Paulis, L. and Simko, F. (2007) Blood Pressure Modulation and Cardiovascular Protection by Melatonin: Potential Mechanisms Behind. Physiological Research, 56, 671-684.

[9] Muller, J.E. (1999) Circadian Variation in Cardiovascular Events. American Journal of Hypertension, 12, 35S-42S. http://dx.doi.org/10.1016/S0895-7061(98)00278-7

[10] Panza, J.A., Epstein, S.E. and Quyyumi, A.A. (1991) Circadian Variation in Vascular Tone and Its Relation to Sympathetic Vasoconstrictor Activity. New England Journal of Medicine, 325, 986-990. http://dx.doi.org/10.1056/NEJM199110033251402

[11] Dodt, C., Breckling, U., Derad, I., et al. (1997) Plasma Epinephrine and Norepinephrine Concentrations of Healthy Humans Associated with Night Time Sleep and Morning Arousal. Hypertension, 30, 71-76. http://dx.doi.org/10.1161/01.HYP.30.1.71

[12] Cunnane, S.C., Manku, M.S., Oka, M. and Horrobin, D.F. (1980) Enhanced Vascular Reactivity to Various Vasoconstrictor Agents Following Pinealectomy in the Rat: Role of Melatonin. Canadian Journal of Physiology and Pharmacology, 58, 287-293. http://dx.doi.org/10.1139/y80-049

[13] Laflamme, A.K., Wu, L., Foucart, S. and Champlain, J. (1998) Impaired Basal Sympathetic Tone and $\alpha 1$-Adrenergic Responsiveness in Association with the Hypotensive Effect of Melatonin in Spontaneously Hypertensive Rats. American Journal of Hypertension, 11, 219-229.

[14] Zhu, H.-Q., Cheng, X.-W., Xiao, L.-L., Jiang, Z.-K., Zhou, Q., Gui, S.-Y., Wei, W. and Wang, Y. (2008) Melatonin Prevents Oxidized Low-Density Lipoprotein-Induced Increase of Myosin Light Chain Kinase Activation and Expression in HUVEC through ERK/MAPK Signal Transduction. Journal of Pineal Research, 45, 328-334. http://dx.doi.org/10.1111/j.1600-079X.2008.00595.x

[15] Blask, D.E., Wilson, S.T. and Lemus-Wilson, A.M. (1994) The Oncostatic and Oncomodulatory Role of the Pineal Gland and Melatonin. Advances in Pineal Research, 7, 235-241.

[16] Pechanova, O., Matuskova, J., Capikova, D., et al. (2006) Effect of Spironolactone and Captopril on Nitric Oxide and S-Nitrosothiol Formation in Kidney of L-NAME-Treated Rats. Kidney International, 70, 170-176. http://dx.doi.org/10.1038/sj.ki.5001513

[17] Antón-Tay, F., Huerto-Delgadillo, L., Ortega-Corona, B. and Benitez-King, G. (1993) Melatonin Antagonism to Calmoduline May Modulate Multiple Cellular Functions. In: Toiutou, Y., Arendt, J. and Pévet, P., Eds., Melatonin and the Pineal Gland-From Basic Science to Clinical Application, Elsevier Science Publishers, Amsterdam, 41-46.

[18] Reiter, R.J., Tan, D.X. and Maldonado, M.D. (2005) Melatonin as an Antioxidant: Physiology versus Pharmacology. Journal of Pineal Research, 39, 215-216. http://dx.doi.org/10.1111/j.1600-079X.2005.00261.x 